\title{
Comparative experimental analysis of the reproductive potential and sexual behavior of house mice from the transcaucasian hybrid zone and Mus musculus
}

\author{
E. Kotenkova*, A. Maltsev, A. Ambaryan \\ Severtsov Institute of Ecology and Evolution RAS, Moscow, Russia \\ *e-mail:evkotenkova@yandex.ru
}

Key words: house mice, reproduction, closely related species, hybridization, hybrid zone

Motivation and Aim: Traditionally hybridization is considered as negative process because hybrids have genomic disruption and as result lower fitness than either parental genotypes. We proceeded from the hypothesis of Milishnikov et al. (2004) that there is large and genetically complicate hybrid zone in Transcaucasia. In this region, in different historical periods, three forms of house mice were hybridized: the first one is genetically close to Mus musculus s. str. preserved a relict gene pool; differentiated M. musculus and $M$. domesticus. In the laboratory, we investigated the fecundity, fertility and sexual behavior of house mice from Transcaucasian populations and M. musculus to evaluate the fitness of natural hybrids and development of reproductive isolating mechanisms. Methods and Algorithms: The breeding parameters were investigated by the method of experimental hybridization. Additionally we investigated weight of testicles, sperm quality and concentration. 90 min dyadic encounters of con- and heterospecific males and estrous females were conducted. Behavior of sexual partners was recorded by a video camera and analyzed by means of Observer Video-Pro, Version 4.1.

Results: Reproductive intensity and indicators of fertility of house mice from Moscow, the Moscow region and from the zone of hybridization in Transcaucasia was similar. M. musculus and Transcaucasian mice were crossed easy in the laboratory. Viability and fertility of $F_{1}$ were ordinary, mortality was higher in one variant of crosses. The sperm quality was reduced lightly only in $\mathrm{F}_{2}$ hybrids. In conspecific encounters males, as well as females of $M$. musculus exhibited affiliative behavior frequently and longer than females of Transcaucasian mice. Differences in duration and frequency of copulatory behavior in total and elements of this behavior in two forms of house mice were not statistically significant. In heterospecific encounters, females as well as males of $M$. musculus, exhibited affiliative behavior less than in encounters with conspecific partners. This also concerns of grooming, naso-nasal contacts and overall duration and frequency of affiliative behavior in female M. musculus.

Conclusion: The data did not support the reduced fitness of Transcaucasian hybrids and the effect of isolating mechanisms between mice from Transcaucasia and M. musculus. The results confirm genetic relationship of these forms.

Acknowledgements: Supported by the Russian Foundation for Basic Research project 16-04-00149. 